IOS Press

\title{
Editorial
}

\section{Editor-in-Chief's Editorial to the Special Issue: COVID-19's Impact on the Practice of Pediatric Rehabilitation Medicine}

As the world seemingly came crumbling down around us, in the San Francisco Bay Area we went from unfettered travel to shelter in place (SIP) on March 17, 2020. We eagerly watched and read the news as it unfolded about this novel coronavirus that transformed our lives so quickly. Following the initiation of SIP, our in-person clinics moved to virtual video visits in a matter of days. The silver lining of these telehealth visits was the ability to evaluate our complex medical patients in their home environment and to actually assess all of their equipment, not limited by what they could bring to the clinic. We thanked each and every family for allowing us to visit them in their home. Our patient's families were grateful to have a familiar medical team provide contact and coach them when many of their PT and OT services were cut during the pandemic. Approximately half the families shared with us during these visits that virtual learning was working out well and they were not anxious for their child to return to school until they were more certain that it was safe to do so.

Throughout the past six months, every aspect of my life has been touched by COVID-19 and the Black Lives Matter movement. To sustain our households, we organized to find flour and baker's yeast to make homemade bread, tried to make our own sourdough starter, and fixed home appliances using YouTube videos as our reference. Our communities put up Black Lives Matter signs and attended protests as part of the public outcry over the brutal killings of George Floyd, Breanna Taylor, and Ahmaud Arbery. As one of many musicians in our neighborhood, we honored the legacy of Marvin Gaye as we belted out "What's Going On" at 7 pm from our porches nightly. On the evening we sang Amazing Grace, Dr. Colleen Wunderlich called from across the country to sing with us. We maintained hope as days turned into weeks and weeks turned into months.

Like many of our colleagues, we have appreciated conferences that were in-person in the past now embracing a virtual platform. In May I attended virtually the Counsel for Scientific Editors (CSE) meeting. This meeting was particularly informative emphasizing that the newer trend in medical journals is to have information in an understandable format for nonmedical readers as well. Not leaving the confines of my home, I gave what was supposed to be an in person grand rounds on physician wellness and suicide, to a complementary virtual audience at Mary Free Bed, in Grand Rapids, Michigan.

At the start of the pandemic, we were emotionally overwhelmed by the COVID-19 numbers in New York City. We saw the disparity of care when the supply of hospital beds and ventilators did not meet the demand. Then, weeks later, once SIP was relaxed, our COVID19 numbers in California went up and surpassed those in New York. However, New York has almost twice the number of deaths than California with almost half the numbers of positive cases [1]. Urgent medical meetings took place across the country and some medical staff were re-purposed without adequate training. In addition, we heard from colleagues that without much warning pediatric rehabilitation units were housing adults either with COVID-19 or other conditions. In July, 2020, Amnesty International reported 3000 medical workers worldwide being mistreated including some who were incarcerated and shamed for complaints of being required to work without enough or proper Personal Protective Equipment (PPE) [2]. As of September, 2020 after contracting COVID-19 at least 7,000 health care workers have died from COVID-19 globally [3]. 
The recommendations on preventing the spread of the virus continued to evolve. At first we were told the virus was transmitted by touching various surfaces and how long the virus lasts on paper, versus plastic versus cardboard and that masks weren't really necessary. Next, scientific evidence revealed masks were an important item to wear to stop the spread of the virus [4]. Soon after the pandemic began, the Multisystem Inflammatory Syndrome in Children (MIS-C) surfaced and became a potential threat to our pediatric rehabilitation patient population [5]. We overnighted oxygen pulse oximeters to many and waited and prayed daily for our colleagues, loved ones, friends and patients that tested positive.

In March 2020, shortly after the SIP was mandated in our county, it became apparent that JPRM needed a COVID-19 special themed issue. Dr. Christian Vercler, a friend and colleague of the late Dr. Jacob Neufeld and Dr. Matthew McLaughlin our pediatric rehabilitation colleague stepped up to the plate for this JPRM COVID-19 special issue that rapidly took on a life of its own. This special issue covers many aspects of COVID19 including the disparate influence on Black, Latinx and Native American marginalized populations; a book review of a "thriller" somewhat predictive of the virus; and the telemedicine experience. It also includes an attorney-written article, as well as the impact of the pandemic on spasticity management, cerebral palsy, neuromuscular disorders, tracheostomies, and on those in medical training. Through this JPRM issue we are disseminating a wealth of information on COVID-19 and the effect that it has on our pediatric rehabilitation care takers, providers and those with special needs. It is my belief that this type of worldwide outreach and exchange of information is an essential part of the global solution to help mitigate the spread of this deadly virus. For example, we had a Norwegian teacher as a peer reviewer, as Norway's strategy helped to successfully transition children back to in-person schools. Additionally, we reached out to other industries for advice. We had a submission from the construction industry regarding a new school building and the safe return of children with special needs. Because of the pandemic we offered authors whose manuscripts were accepted in what would have been the 13.3 open issue the opportunity to include COVID-19's impact on the subject matter of their article. Each and every editorial, commentary and research paper was peer reviewed.

In the midst of a global pandemic, the editorial office has simultaneously been immersed in multiple special issues throughout 2020 . We started the year with an open issue, followed by the cerebral palsy special issue with Drs. Deborah Gaebler-Spira and Michael Green as our seasoned guest editors. Following this COVID-19 special issue we will culminate 2020 with our yearly spina bifida special issue featuring open access guidelines with guest editors Drs. Timothy Brei, Heidi Castillo and Jonathan Castillo. A special thank you to our JPRM managing editor, Sara Tinsley.

On October 23, 2020, in an interview on the PBS Newshour, the director of the NIH, Dr. Francis Collins, talked about the likelihood and timing of the COVID19 vaccine. He remarked that if trials are successful, the vaccine will likely be widely available about a year from now. If it isn't successful or if not enough of the population accepts the vaccine, we will be contending with the virus for a long time to come. Immediately, I thought of the late Dr. Jacob Neufeld (the founder of JPRM) and his writings regarding Dr. Ignaz Semmelweis, a Hungarian physician and scientist who was actually ridiculed for proposing that those delivering babies wash their hands before doing so. Dr. Semmelweis, who died in an insane asylum, is known for the Semmelweis effect and posthumously a medical school was named after him. Many other physicians and scientists have proposed ground breaking treatment options, and have been ostracized and harshly criticized. This list includes Dr. Rene Laennec who invented the stethoscope in 1816 and Dr. Emil J. Freireich, a trailblazing oncologist who cured childhood leukemia, and received many threats to his medical career in the process [5]. Dr. Anthony Fauci, the director of Allergy and Infectious Disease of the NIH has received blatant threats and bullying for his altruistic efforts to reduce the number of COVID-19 infections and resultant deaths that have touched all of our lives.

John Lewis our dear civil rights leader and senator had a famous slogan: "When you see something that is not right, not fair, not just, you have to speak up. You have to say something; you have to do something." Each time I see someone without a face mask in public, I fear for our medical and nonmedical community.

Wearing a mask helps all of us. Using protective masks and placing our nose and mouth within these should not be any more controversial than following HIV precautions. As of 2018, about 700,000 people have died from HIV/AIDS in the U.S. since the beginning of the HIV epidemic approximately 40 years ago. In 2018 there were 15,820 deaths among those with HIV in the United States and dependent areas (American Samoa, Guam, the Northern Mariana Islands, Puerto Rico, the Republic of Palau and the US 
Virgin Islands). From 2014 to 2018 the annual number of new HIV diagnoses decreased by $7 \%$ [6]. In the 6 months since the pandemic started, we have lost over 220,000 lives in the United States and 1.15 million globally [1]. HIV precautions and protection are widely practiced; the numbers of those infected by HIV would not be as contained as they are today without this. There is no current effective vaccine for HIV and we do not know when the COVID-19 vaccine will be widely available, and if it will be effective once it is. Similar to HIV, there is no guarantee that once an individual has COVID-19 that there will be immunity or that a subsequent infection will have a better or worse clinical course. The NIH reports that COVID-19 "represents the greatest medical challenge in decades" with cardiac sequelae as a potential serious side effect [7]. In addition, our pediatric rehabilitation patients are at greater risk of MIS-C [5]. These are all good reasons to take COVID-19 as seriously as we do HIV.

During this global pandemic we lost supreme court justice Ruth Bader Ginsberg who was a powerful example of someone who wasn't afraid to voice her beliefs. Let's stand up like the great John Lewis, Ruth Bader Ginsberg, Drs. Semmelweis, Laennec, Freireich, Collins and Fauci. Let's raise each other up like Dr. Neufeld did. Our lives, livelihood and those we love and hold dearly are at stake in this unprecedented time. While embracing differences, our future depends on us working together to solve this world wide crisis. JPRM engages a diverse group of experts and reaches out to almost every country in the entire world (200 countries). This journal is a wonderful vehicle for disseminating information in our commitment to improve the care we provide for those with complex medical care needs.

\section{References}

[1] Johns Hopkins University \& Medicine. Coronavirus Resource Center. Available from: https://coronavirus.jhu.edu/.

[2] Global: Health workers silenced, exposed and attacked. Amnesty International. Available from: https://www.amnesty. org/en/latest/news/2020/07/health-workers-rights-covidreport/.

[3] Global: Amnesty analysis reveals over 7,000 health workers have died from COVID-19. Amnesty International. Available from: https://www.amnesty.org/en/latest/news/2020/09/amnesty -analysis-7000-health-workers-have-died-from-covid19/.

[4] Anderson EL, Turnham P, Griffin JR, Clarke CC. Consideration of the Aerosol Transmission for COVID-19 and Public Health. Risk Anal. 2020; 40(5): 90-907. doi: 10.1111/risa.13500

[5] Gladwell, M. David and Golliath. Underdogs, Misfits, and the Art of Battling Giants. New York: Little Brown and Compan, 2013.

[6] Viner RM, Whittaker E. Kawasaki-like disease: emerging complication during the COVID-19 pandemic. Lancet. 2020 Jun 6; 395(10239): 1741-1743. doi: 10.1016/S0140-6736(20)31129-6

[7] Centers for Disease Control and Prevention. Basic Statistics. Available from: https://www.cdc.gov/hiv/basics/statistics.html.

[8] Guzik TJ, Mohiddin SA, Dimarco A, Patel V, Savvatis K, Marelli-Berg FM, et al. COVID-19 and the cardiovascular system: implications for risk assessment, diagnosis, and treatment options. Cardiovasc Res. 2020 Aug 1; 116(10): 1666-1687. doi: $10.1093 / \mathrm{cvr} / \mathrm{cvaa} 106$

Sincerely yours,

Elaine L. Pico, MD, FAAP, FAAPM \& R

Editor-in-Chief

E-mail: elaine.pico@ucsf.edu 